\title{
Extractive entanglements and regimes of accountability at an underdeveloped mining project
}

\author{
Emilia E. Skrzypek
}

\begin{tabular}{|l|l|}
\hline Date of deposit & 17052021 \\
\hline Document version & Author's submitted manuscript \\
\hline Access rights & $\begin{array}{l}\text { The preprint version prior to peer-review is Copyright C } 2021 \text { the } \\
\text { Author. This version was submitted to the Resources Policy } \\
\text { Journal in July 2019. It has since been amended and published (in } \\
\text { July 2020) following peer review. Please do not circulate it } \\
\text { without the author's consent. }\end{array}$ \\
\hline $\begin{array}{l}\text { Citation for } \\
\text { published version }\end{array}$ & $\begin{array}{l}\text { Skrzypek, EE 2020, 'Extractive entanglements and regimes of } \\
\text { accountability at an undeveloped mining project', Resources } \\
\text { Policy, vol. 69, 101815. }\end{array}$ \\
\hline $\begin{array}{l}\text { Link to published } \\
\text { version }\end{array}$ & https://doi.org/10.1016/j.resourpol.2020.101815 \\
\hline
\end{tabular}

Full metadata for this item is available in St Andrews Research

Repository at: https://research-repository.st-andrews.ac.uk/

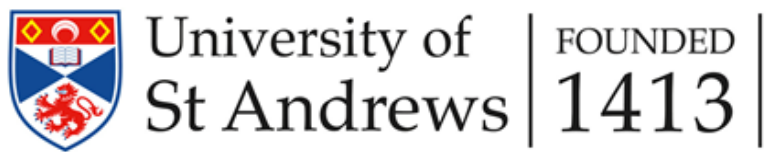


This version was submitted to the Resources Policy Journal in July 2019. It has since been amended and published (in July 2020) following a peer-review. Please do not circulate this copy without the author's consent. Published version for citation can be found here: https://doi.org/10.1016/j.resourpol.2020.101815

\section{Extractive entanglements and regimes of accountability in undeveloped mining projects.}

\section{Introduction}

This paper analyses the role of CSR in framing company's engagement with local stakeholders at the Frieda River Project - an advanced copper and gold exploration venture in the upper Sepik region of Papua New Guinea. Frieda River area is home to one of the largest undeveloped copper and gold ore bodies in the Pacific. It is an example of what Valenta et al. (2019) identified as a 'complex orebody', where this complexity extends beyond geological characteristics of the deposit, and includes a range of environmental, social and governance (ESG) factors. Frieda River displays a number of characteristics which Valenta et al. used to identify and define complex orebodies. The size of its copper reserves makes Frieda River a world class deposit, but the grade of the mineral is relatively low meaning that any future extraction will require significant input of water and energy, and will likely produce high volumes of waste, resulting in a large environmental footprint project. The deposit is located in a remote and ecologically sensitive area, in the tributary of the Sepik River; on a land belonging to indigenous communities with limited access to basic services and very poor civic infrastructure; and in a country grappling with poverty and corruption. Valenta et al. argued that although risks associated with ESG factors may not be price sensitive in the immediate term, rapid unlocking of these ore bodies to meet global demand for minerals will unleash some very complex impacts and can threaten the future of individual projects. Their findings highlight the importance of improved knowledge about ESG factors at undeveloped copper ore bodies such as Frieda River, and suggest that the way in which companies manage those complexities, engage with local stakeholders, and negotiate and act on their responsibilities, may have a deciding effect on the future of the projects, and influence future mining industry's ability to meet future demands for copper.

The material presented here demonstrates that the way the company operating the Frieda River Project has talked about CSR, and put its CSR commitments into practice, points to lack of comprehension of the complexity of the project setting. In this example, discourse of CSR, and its enactments in the project location, may have served to simplify a 'complex ore body', increasing the project's vulnerability to ESG 
This version was submitted to the Resources Policy Journal in July 2019. It has since been amended and published (in July 2020) following a peer-review. Please do not circulate this copy without the author's consent. Published version for citation can be found here: https://doi.org/10.1016/j.resourpol.2020.101815

risks. The paper builds on existing accounts describing ways in which resource extraction companies use CSR in a way that demonstrates 'ethics of detachment' (Cross, 2016; Gardner, 2016) and promotes a position of disentanglement from local contexts and obligations (Welker, 2014; Appel, 2012a and 2012b). It broadens the scope of scholarship to date, focused almost exclusively on already operating mines, by looking at an undeveloped orebody. The paper shows that while discourse of CSR brings the entanglements at resource projects to light, mainstream CSR practice can serve to distance companies from the impacts of their operations, and facilitate a process of disconnection from local realities and obligations. It uses an example of the Community Relations and Community Development (CRD) field practitioners at the Frieda River Project to contrast the professional and detached arenas in which CSR mechanisms tend to be strategically developed, with the entangled and deeply relational contexts in which they are implemented on the ground in the project location. The paper develops Gilberthorpe and Banks's (2012) critique of mining companies' emphasis on externally set targets over local outcomes, and links their preoccupation with auditable standards to forms of accountability and ways in which CSR is operationalised in companies, and enacted in project locations. Extending Kemp's (2010) arguments about positioning of CRD function within mining companies, material presented here highlights unutilised potential of CRD field practitioners to use their knowledge to contribute to the shaping of CSR strategies and CRD programmes in ways that reflect local aspirations, and that respond to rather than neglect and push aside complexities of the operating environments.

\section{2. (In)tangible responsibility}

In the absence of a single, normative definition, CSR can possibly best be best described loosely as 'a bundle of practices and actions that take into account the expectations of diverse stakeholder groups and the triple bottom line of economic, social, and environmental performance' (Hunoldt et al., 2018:2)1. Despite a great wealth of practitioners' accounts and academic analyses of the topic, little about CSR remains incontestable and uncontested. The concept has been operationalised and interpreted differently

\footnotetext{
${ }^{1}$ See also Carroll (1999) for the history of the concept and definition of CSR, and Dahlsrud, 2008 for his analysis of 37 definitions of CSR.
} 
This version was submitted to the Resources Policy Journal in July 2019. It has since been amended and published (in July 2020) following a peer-review. Please do not circulate this copy without the author's consent. Published version for citation can be found here: https://doi.org/10.1016/j.resourpol.2020.101815

by different people and organisations and, as argued by Blowfield (2007), its actual impact on business prospects and development outcomes for host communities remains largely unknown. While the win-win rhetoric points to synergistic value creation potential of CSR activities, the concept has been widely critiqued as a powerful means of self-regulation that both avoids external controls and simply measures its own measurements, grounded in a neoliberal market thinking that 'the best regulation is selfregulation' (Bebbington et al, 2008:900) and a common private sector belief which echoes Friedman's (2007[1970]) famous argument in claiming that 'the most important thing a corporation can do for society, and for any community, is contribute to a prosperous economy' (Porter and Kramer, 2006:13). In possibly the most comprehensive account of CSR practice in mining contexts to date, Dinah Rajak (2011a, 2011b) described how, counterintuitively perhaps, CSR promotes the private sector as the solution to poverty and welfare increasing, not challenging, its power over government and communities. 'Not because it provides corporations with ethics' she wrote 'but because it provides them with a moral mechanism through which their authority is extended over the social order' (Rajak, 2011a:13).

There now seems to be an implied acceptance of CSR principles by virtue of commitments across much of the industry, evidenced by emerging international frameworks, material due diligence processes and bureaucratic artefacts of CSR (such as performance standards and CSR reports). In demonstration of their commitment to those principles, many companies employ on the ground practitioners, tasked with building positive relationships with communities in the local area, and securing their support for the project - what is commonly known in the industry as a 'social license to operate' or an SLTO. Global patterns in supply of mineral resources, tied to inflexible geographies of mineral geology, place many resource exploration and extraction projects in remote areas, inhabited by people with limited access to services, income earning opportunities and state development assistance. Consequently, Kemp (2010) noted that there has been an observable shift moving community relations away from its initial affiliation with public relations, and closer to community development function, with designated Community Relations and Community Development departments becoming a common feature at resource extraction projects and community development emerging as 'a distinct domain of practice in mining' (Kemp, 2009:204). This paper uses Community Relations and Development (CRD) as a shorthand to describe 
This version was submitted to the Resources Policy Journal in July 2019. It has since been amended and published (in July 2020) following a peer-review. Please do not circulate this copy without the author's consent. Published version for citation can be found here: https://doi.org/10.1016/j.resourpol.2020.101815

these functions in mining companies, whilst acknowledging a level of variation that exists across the industry with regards to function structure (some companies have separate Community Relations and Community Development departments, in others this function is merged), and terminology used to describe it (e.g. Community Relations; Community Affairs; External Affairs; Community Engagement; Community Development).

Early CSR discourse in the industry was largely promised around contributing to SD (as evidenced, for example, by the Mining Minerals and Sustainable Development project), and this emphasis continues (despite growing acknowledgement that, like CSR, SD is also poorly understood and amorphous as a concept and operational goal). There now exists a plethora of CSR standards, organizational guidelines and policies, ranging in scale from broad initiatives such as the Equator Principles and Global Reporting Initiative frameworks, to operations-level mechanisms (e.g. grievance management systems and stakeholder engagement strategies), largely structured around the three pillars of SD (economy, environment, society). Those continue to increase in volume as businesses hesitantly acknowledge that maintaining a positive CSR record and engaging in CRD activities while not 'their core business' has become 'core to their business', as demonstrated by Kemp and Owen (2013). Managing social and environmental performance of the extractives sector has become an industry in its own right, with companies commonly relying on contracted consultants, social scientists and development experts for identifying and operationalizing appropriate CRD activities and producing accounts of their contribution to SD. Despite high levels of reliance on external expertise in the CRD space, research consistently points to the role of internal champions and designated CSR personnel in driving the agenda within companies and individual operations. Accounts to date highlight the role of CSR managers and their personal values in the operationalization of CSR and 'their commitment to keep these values alive in the organisation' (Duarte, 2010:358) among increasing interest in the ways in which companies are enacted by individuals working in complex social, political and economic contexts. The 'enactment' approach promotes an analytical model of a company 'as relations and processes, always shifting, unstable, and insecure, rather than instantiations of Homo economicus who know just what they want and how to get it' (Welker, 2014:31), whilst acknowledging ways in which companies strive for order and systematization. Existing 
This version was submitted to the Resources Policy Journal in July 2019. It has since been amended and published (in July 2020) following a peer-review. Please do not circulate this copy without the author's consent. Published version for citation can be found here: https://doi.org/10.1016/j.resourpol.2020.101815

literature demonstrates how individual managers push for budgets and resources, 'frame CSR in a way that allows them to "sell" it to other interest groups within the organisation' (Hunoldt et al, 2018:3), and 'try develop measures of success to signal CSR's importance to other departments' (ibid.:20) even where this importance is not well understood in other parts of the company, as described by Duarte (2011) in the context of Brazilian mining companies. There is, however, less ethnographic exploration of experiences of field practitioners tasked with enacting 'a socially responsible company' and performing the CRD function in project localities.

\section{Tangled up}

The extractive industries' engagement with CSR emerged out of a recognition of broader social and environmental impacts of their operations, and the need to acknowledge responsibility for those. Although the companies favour the language of stakeholder engagement, and risk and impact management to describe business rationale behind CSR and, ultimately, CSR reflects recognition of complex and numerous entanglements at resource extraction projects - aptly termed by Bainton and Owen as 'zones of entanglement' (2018). As described by Appel (2012a) in her study of oil extraction operations in Equatorial Guinea, acknowledged responsibility is in itself a form of inherent entanglement, which places companies at the heart of the web of relations and obligations. But companies prefer to be alone with their routines and push towards limiting outside interference in their running and operations. The industry's experience to date shows that companies actively try to control the remit of their obligations and their relationship with their external operating environment, and seek to abdicate of responsibility for what happens outside clearly defined zones of their core activity. Using an example of company camp infrastructure, Appel spoke of the 'industry's efforts to disentangle the production of profit from the place in which it happens' and to 'structure liability and responsibility in such a way that [it] can remove itself from the social, legal, political, and environmental entanglements in which it is so deeply enmeshed' (2012a:442, see also Appel, 2012b).

Discourse of CSR promotes wider responsibilities of companies and places upon them a duty to engage in activities that are often beyond the scope of their core operations. In some ways, as described by Harvey 
This version was submitted to the Resources Policy Journal in July 2019. It has since been amended and published (in July 2020) following a peer-review. Please do not circulate this copy without the author's consent. Published version for citation can be found here: https://doi.org/10.1016/j.resourpol.2020.101815

(2014), it requires businesses to act un-business-like, causing companies to push back on expectations of their CSR practice and find ways in which they can conceptually combine their operational priorities with the wider social obligations. In his famous critique of CSR Henry Mintzberg (1983) pointed out that companies lack the expertise to pursue social goals and that, by the very nature of their activities, they create rather than resolve social problems. Some years later, Humphreys (2000) argued that faced with those persisting limitations and under pressure to demonstrate their commitment to CSR, for example through performing a CRD function in project localities, mining companies tend to approach the task in the best way they know how - by attempting to treat them as a business issue which must be dealt with and replicate business and engineering solutions to address social and moral concerns.

In search of ways to operationalise CSR, the industry rallied around the idea of developing replicable solutions and standardised responses, endorsed by prominence of global standards and best practice guides (in the context of the mining industry these include, for example, the ICMM Sustainable Development Framework or the Extractive Industries Transparency Initiative Standards). In her comparative study of one mining company's operations in Ghana and Peru, Sydow described how the company attempted to implement standardised solutions in two very different operating contexts. In doing so, it followed its global model for local stakeholder engagement, developed 'in abstraction from the particular contexts of operations' and aimed at producing 'standardised, manageable outcomes' (2016:218). She drew parallels between Scott's (1998) ideas on legibility, which award prescribed categories and labels with particular types of influence, and CSR models, which produce standardised view on communities to make them, for the company at least, manageable, and the relationships between the two governable. In both cases, Sydow (2016:218) argued, the standardisation served to impose order, exercise control, and depoliticise 'both the causes of poverty and the development measures deployed to address them'.

Ferguson (1990) and, more recently, Banks et al. (2017) demonstrated that once depoliticised and decontextualized, even the most complex social issues can be turned into technical exercises for which solutions can be found. This, in turn, incentivises companies to present problems in ways which allow 
This version was submitted to the Resources Policy Journal in July 2019. It has since been amended and published (in July 2020) following a peer-review. Please do not circulate this copy without the author's consent. Published version for citation can be found here: https://doi.org/10.1016/j.resourpol.2020.101815

them to emerge as a solution and where business, technology and science can offer an explanation and a way forward, as in the case of the mining company described by Rajak (2011a). The way in which companies measure, monitor and ameliorate local effects of their operations is important here. In her account of a Texas-based mining company operating in Indonesia, Welker (2014) described how the company was largely indifferent to its impact on the lives of individuals affected by their operations and instead caught up in a quest for metrics and evidence of trends that made these impacts visible. This indifference, Welker explained, was facilitated by technologies of calculation, where success or failure of care extended by the company to its employees and the local people was measured by clearly defined, objective indicators, unsympathetic to personal circumstances and scenarios - making the 'care' and social goals abstract and largely removed from local and personal contexts. Once abstracted from on-theground realities in mining locations, she argued, this care was best managed from a position of disentanglement. This led executives at the company headquarters to see themselves as more progressive and enlightened, better able to make the right, objective decisions than the site-level managers and staff who were caught up in complex local networks of care, responsibility and reciprocity with mine workers and members of local communities.

Herein lie some of the paradoxes of CSR which I want to explore in here. While it emerged out of a recognition of a complex web of entanglements, mainstream CSR practices tend to promote disentanglement by favouring solutions that are developed and assessed remotely, away from the site of operations. While it recognises the cultures and rights of communities affected by industry's operations, it employs an apparatus of CSR which prioritises industry targets while disregarding local goals, and which values decontextualized solutions and disentangled expertise over locally co-created ideas for managing and leveraging the impacts of their operations. While it was born out of recognition of the power of companies over large parts of the society, put into practice CSR seeks to treat power differentials as externalities and operates through a lowest common denominator mechanism which presents all actors as equal excluding much of local context and seeking to depoliticise inherently political practices and relations. As a consequence, at resource extraction projects, the real issues and differences are all too often expressed and dealt with through conflict and disruptions which Newell (2005) described as 
This version was submitted to the Resources Policy Journal in July 2019. It has since been amended and published (in July 2020) following a peer-review. Please do not circulate this copy without the author's consent. Published version for citation can be found here: https://doi.org/10.1016/j.resourpol.2020.101815

informal local strategies for holding companies accountable for the impacts of their operations on social and development outcomes.

\section{Regimes of accountability}

In most basic terms, accountability is one person or organisation's duty to provide information to another who has the right to request it. This paper broadens this definition by considering accountability and accounting in terms of 'reporting' and 'demonstrating' companies commitment to CSR, as well as substantive and moral accountability embedded in the expanded notion of CSR which demonstrates obligations that companies have to communities. Highlighting the limitations of CSR, Newell argued for the value of the notion of accountability which, in his view, 'lays bare the power relations which are the seemingly benign language of "responsibility" and "citizenship" seeks to deny and obscure' (Newell, 2005:542). Although most commonly associated with financial disclosure, the emergence of CSR was accompanied by popularization of what Gray (2002) brands as 'new accounting', which aims to capture and make visible social and environmental outcomes at business operations. Commonly known as social accounting or sustainability accounting, the practice constitutes an exercise closely related to compulsory financial disclosure but often seen as its more reflexive and self-conscious cousin, 'a cultural and social process as well as something rooted in formal structures and roles' (Newman 2005:29). Unlike mainstream accounting which produces an auditable account of a company's financial performance, 'social accounting produces a narrative that acquires symbolic power, directing legitimacy and power to the company, while restructuring the community's social relationships, self-identify and patterns of accountability' (Killian and O'Regan, 2016:1, see also Böhling et al. 2019). In principle, those new models of account making create space for a more interactive engagement where 'relationships among multiple actors are negotiated, reproduced and reinforced' (Kemp et al, 2012:2).

In practice, however, big companies especially find it difficult to escape the prescriptions of what Power $(1999,2000,2003)$ calls the audit culture that uses universal standards to assess the strength of business' performance, tying companies' ability to claim good citizenship to their aptitude to make their social relations and responsibilities appear in a specific form, which can then be assessed against a series of 
This version was submitted to the Resources Policy Journal in July 2019. It has since been amended and published (in July 2020) following a peer-review. Please do not circulate this copy without the author's consent. Published version for citation can be found here: https://doi.org/10.1016/j.resourpol.2020.101815

clear and widely recognised parameters. As succinctly expressed by one mining company CEO quoted by Sydow (2016:238): 'what gets measured gets managed'. This process has been criticised for detaching social accounting from reality, and for creating a gap between the moral and relational argument for accountability, and the actual practice of social accounting. In the context of Papua New Guinea's mining industry, Macintyre et al. (2008:108) argued that "complex operations [make] themselves "auditable" by abstracting from first-order performance objectives and focusing instead on management systems for defining and monitoring performance', shifting emphasis from the baseline questions of quality of relations between the company and its stakeholders to management systems, and from the realistic objectives driven by social interactions to dangerously standardised products of management systems approach. In illustration of this process Newell (2005) described instances where, he argued, companies use social accounting mechanisms to claim good citizenship, whilst being simultaneously engaged in ground-level disputes about realisation of their duties and obligations towards local stakeholders.

From an institutional perspective, the two functions are performed by different personnel in different parts of companies. Although information may be sourced from various departments within the organisation, sustainability reports tend to be produced away from ground-level operations in companies' headquarters and main offices. Depending on the size of organization, these can be produced by designated sustainability and external relations departments, although instances where reporting is done by communications and PR personnel are not uncommon. Data is digested, standardised and selectively presented in a way that sets out to demonstrate the companies' contribution to environmental and social goals of sustainable development. The reports are then used by companies to 'explain and justify their activities in areas that are considered important by influential segments of society, including the public at large' (Sethi et al., 2016:220). On the ground, the task of explaining and justifying company activities falls to CRD practitioners. In general terms, the CRD field personnel at resource exploration and extraction projects are tasked with 'assisting operations to manage their immediate external relationships so as to provide an operating context that is conducive to achieving the company's goals and objectives, while meeting the expectations of local communities for respect and reciprocity often in the form of "development"” (Kemp and Owen, 2013:527). In order to fulfil their roles, they enter into and oftentimes 
This version was submitted to the Resources Policy Journal in July 2019. It has since been amended and published (in July 2020) following a peer-review. Please do not circulate this copy without the author's consent. Published version for citation can be found here: https://doi.org/10.1016/j.resourpol.2020.101815

facilitate complex and dynamic social networks in project locations. They interact with local stakeholders on regular basis, and their ability to do their roles, and to do them well, requires them to create and manage numerous personal relations, responsibilities and obligations. They get socially entangled - to use terminology introduced above - in local contexts.

By definition and design, CRD field practitioners occupy difficult and contested spaces in-between prescriptions of company management and operational systems, and the reality of social relations and localised impacts of company activities. This places them in a unique and difficult position of dual accountability, caught up between management targets, and local regimes which make them personally accountable to community members they interact with in project locations. As demonstrated by Owen and Kemp (2014), while they play an increasingly important role at resource extraction project, they tend to have limited to resources and decision-making power and their experiences are poorly understood institutionally and in business and management literature. The next section of this paper uses interview data and ethnographic material collected at the Frieda River Project in Papua New Guinea to illustrate how members of the Project's Community Affairs team understood and managed the demands of their jobs, and how they navigated the difficult terrain in-between relationships, roles and expectations.

\section{Community Affairs at the Frieda River Project}

Located in a geographically remote part of Papua New Guinea, on the border between the country's Sandaun and East Sepik Provinces, the Frieda area is home to one of the largest undeveloped copper and gold deposits in the Asia-Pacific region. As described above, unlike the already operating resource extraction projects studied by Rajak, Cross, Gradner, Sydow, Appel and Welker, Frieda River is a resource exploration project. The mineral prospects were first identified at Frieda during a regional mapping exercise in 1966, and the Exploration License was granted three years later. Exploration has been ongoing since, but has noticeably intensified in 1996 when, Highlands Gold Properties Pty Ltd completed the first full feasibility study for the project. Most recent plans for the venture describe the Frieda River Project as a 'a core component of a transformative nation-building opportunity - the Sepik Development Project' promised to deliver broad socio-economic uplift, 'improve transport and 
This version was submitted to the Resources Policy Journal in July 2019. It has since been amended and published (in July 2020) following a peer-review. Please do not circulate this copy without the author's consent. Published version for citation can be found here: https://doi.org/10.1016/j.resourpol.2020.101815

connectivity, facilitate the delivery of services to remote communities, and boost domestic and international trade and investment' (PanaAust, 2018:1). For the time being, however, the project footprint is condensed largely to a relatively small population living in seven so-called impact communities, and its future remains uncertain. In 2011 the project was operated by Xstrata Frieda River Ltd - a PNG registered company, with headquarters in the country's capital, Port Moresby. The company was embedded within a much larger, Australia-based parent institution, Xstrata Copper, which at the time was the fourth largest copper producer in the world. Both Xstrata Frieda River Ltd and Xstrata Copper belonged to a global diversified business group, Xstrata Plc. with headquarters in Zug, Switzerland, and a registered office in London, United Kingdom. Xstrata Frieda River followed Xstrata plc Sustainable Development (SD) policy and 17 SD standards develop in the Zug HQ, and its CSR reporting followed the GRI G3 Sustainability Reporting Guidelines.

The company operated two main camps in the Frieda area: the Airstrip Camp, easily accessible from three of the impact communities; and the Base Camp, reachable by a helicopter shuttle from the airstrip. Project personnel worked on a fly-in-fly-out roster, with workers flown into the area on a company fixed wing charter from other parts of PNG and Australia. In general terms, company activities were divided into two distinctive domains. The first one was the operations division, headed by the operations manager and responsible for the daily running of the company's on-site activities. The second was a team of CRD field practitioners, known at the project as Community Affairs (CA) officers. The team was established when Xstrata took over the management of the Project in 2007. As described in the company's sustainability report for that year, it was tasked with enacting the company's CSR ethos and Community Relations policies; fine tuning and delivery of the company's Community Development Plan; and ensuring efficient and clear communication and good relations between the Project's local stakeholders (Xstrata, 2008). Initially the team consisted of a manager and three officers who faced the task of 'building community relations from scratch' as none of the CA employees working at Frieda under previous management decided to stay on. Over time, the team grew. It fluctuated in size, but in 2011-12 it generally consisted of three superintendents, two of whom were expatriates and all of whom were male, and seven to eight officers (a mix of men and women). Almost all of them were recent university graduates recruited and 
This version was submitted to the Resources Policy Journal in July 2019. It has since been amended and published (in July 2020) following a peer-review. Please do not circulate this copy without the author's consent. Published version for citation can be found here: https://doi.org/10.1016/j.resourpol.2020.101815

brought to Frieda from different parts of Papua New Guinea. None of the officers came from the impact communities. A couple of senior team members had a previous first-hand experience of working at one of the country's already operating resource extraction projects, But for most, working at Frieda was their first up-close encounter with the process of stakeholder engagement in mining contexts. The team was led by a Brisbane-based CA manager who made infrequent visits to the site.

When they commenced their employment, each CA officer received a job description. The description was long and detailed, and based on an equivalent role at an already operating mine. The duties seemed similar, but the officers thought a lot of it was not relevant for work at an exploration project. There was also no job specific induction for new team members, no set template procedure. This left the officers to, as one of them put it, 'figure things out for themselves'. In 2011 the CA officers stayed in the Airstrip Camp and the team occupied a newly erected, large and well equipped office located near the Camp's entrance gate. Members of local communities were allowed to cross the gate, but did not have the permission to go past the CA office and into the camp without invitation and appropriate authorization. In 2012 the CA team was moved to the more remote Base Camp, limiting the ad-hoc interactions between the officers and the locals. Team members were not consulted about the move:

It was an Operations decision. They told us we should be happy that we get less disturbed by the locals in the Base Camp. That we should enjoy. But that was opposite to our function.

The CA officers routinely described themselves to me as 'bridging elements' and 'mouthpieces' working between the company and communities. For many community members 'the CAs', as they referred to them, were the company. This often placed the latter at the receiving end of communities' complaints and requests and meant that the officers were often held personally responsible for the company's decisions - especially when those were not to the communities' liking. All of the CA officers I encountered at Frieda linked their ability to do their jobs and to do them well to their ability to 'really get to know the communities' which they achieved through regular contact and forming personal relationships with community members. The team made frequent visits to the seven villages, and every morning, at 08.00 am, one of the team members would attend to a radio duty. CB radios were installed in all of the Project's 
This version was submitted to the Resources Policy Journal in July 2019. It has since been amended and published (in July 2020) following a peer-review. Please do not circulate this copy without the author's consent. Published version for citation can be found here: https://doi.org/10.1016/j.resourpol.2020.101815

impact communities when Xstrata took over management of the Project and every day, at 8:00 o'clock, in words of one of the CA officers, 'messages and stories were exchanged and relationships forged'. Forming meaningful relations with members of local communities became one of the most difficult and most important tasks for the team members. Some of those relations were deeply personal, and many were based on actions and encounters which extended beyond the CA roles as prescribed by their standardised and ill-fitting job descriptions. The CA officers entered into their own care and reciprocity relations with members of the communities for which they felt responsible, and were genuinely affected by events and developments therein. As one of them put it: 'We are the section of the company that really cares for the people and which takes on their concerns'.

\section{Sustainability as mitigation of liability}

Despite their role and work portfolio being embedded within the company's CSR standards, the CA officers rarely spoke of CSR. When asked directly they were most likely to respond by saying that CSR is 'something for the big bosses in their offices'. In their view, CSR happened 'at a higher, management level' and was largely absent from their own ground work at Frieda. While the CA officers did not use the language of CSR, they often talked about sustainability and SD. In the context of their role in the project location, they mostly saw sustainable development in terms of community development, and considered it to be the on-the-ground dimension of CSR. A large proportion of CA officers took SD to literally describe the local capacity to sustain the attributes of development brought about by the Project following either the mine closure or the company's departure from the area, should the Project not progress to the construction phase of its life cycle under Xstrata's management.

The company's public reports talked about establishing community development programs which would bring long term benefits to impact communities, conceptually merging community development with sustainable development. In a way, community development was promoted as means of compensation for surrendering some of their land to mining, and allowing for the proposal to be packaged and promoted locally, nationally and - through sustainability reports produced by the company - internationally as a 
This version was submitted to the Resources Policy Journal in July 2019. It has since been amended and published (in July 2020) following a peer-review. Please do not circulate this copy without the author's consent. Published version for citation can be found here: https://doi.org/10.1016/j.resourpol.2020.101815

win-win situation. This resonated well with local communities, who had very limited access to government services and looked up to Xstrata to bring development to the area. The company had a Community Development Plan, which was developed in Brisbane in consultation with external experts. Once a year, the CA team at Frieda would get together for a workshop where they would take the plan and use their local knowledge to make it workable - setting schedules, allocating tasks, and discussing any community issues, which might affect the delivery of the plan. 'All the intelligence and little gossip gathered from visiting communities' aided this process. The plan gave them direction, and set constraints on the team's activities. The company's management in Brisbane used the language of sustainability and social responsibility to justify their decisions to restrict community development programmes and involvement in delivery of infrastructure and services in the impact communities. In their interpretation, and considering uncertainties of the project, 'sustainability' meant that they should not roll out any programmes that could not be sustained locally in the event of the company's withdrawal from the area. For example, the company placed restrictions on its support for establishment of local schools, which was considered the government's responsibility.

If we introduce a service - will we continue providing it? And if we leave - can it be sustained? Everything we do, we must consider those questions. That is what they tell us.

There were two other factors that placed restrictions on CA activities. Firstly, despite long history of exploration the Frieda River Project was not an operating mine. This meant that it accrued significant cost not offset by any income. In the absence of the final decision regarding the future of the Project under Xstrata's management, the company carefully managed its budgets and placed strict limits on the spending on CRD programmes. The officers were very aware of these financial constraints and understood the need for limiting costs, especially in the light of high community expectations. But they often remarked that the higher levels of company management must be willing to invest, also financially, if they want to benefit from a strong relationships with the communities. They spoke about the ease with which decisions to limit development assistance could be made from a distance of Brisbane offices, and 
This version was submitted to the Resources Policy Journal in July 2019. It has since been amended and published (in July 2020) following a peer-review. Please do not circulate this copy without the author's consent. Published version for citation can be found here: https://doi.org/10.1016/j.resourpol.2020.101815

the difficulties of communicating and explaining those decisions locally, whilst trying to maintain positive relations with local communities and secure their ongoing support for the Project.

The company talks about maintaining the Social License to Operate. But we also have a Personal License to Operate we must maintain here.

Secondly, although almost all of the CA officers I spoke to at Frieda saw their role as essential to the success of the Frieda River Project, many of them did not feel that the importance and the challenging nature of their role were fully recognised by company's other departments. They found themselves in competition with the Project's Operations Division over access to financial, time and logistical resources, which situation was made even more difficult by the severity of local topography. 'It is like there are two camps here. Us and them, CA and Operations' - one of the CA officers told me. 'It is difficult to do things when it is the Operations who have the last say' - I heard from another. 'Sometimes people ask us to come, but the helicopter is busy. So we come very late. But at least they know that we will be there' she later added. Securing access to the helicopter became even more difficult after the team's relocation to the Base Camp. Shortly after the move, the company implemented so-called 'helicopter flying days' which meant that, except for in case of emergency, CA officers trips to communities were limited to particular days during the week. In view of one of the officers, this power imbalance was particularly frustrating considering disparities in the level of education between the sections. While all members of the CA team were university graduates, most of administration, HR, camps and logistics personnel had little formal education.

It is like they speak a different language and cannot understand the value of what we do here. Convincing them to support us takes a lot of time we sometimes don't have.

The above quote describes disconnect at the individual level, between employees from different backgrounds. It is also representative of the systemic failure to embed CRD function within the business, which often demonstrates in other departments' lack of understanding of the CRD function, what it is about, and what role it plays at the project. 
This version was submitted to the Resources Policy Journal in July 2019. It has since been amended and published (in July 2020) following a peer-review. Please do not circulate this copy without the author's consent. Published version for citation can be found here: https://doi.org/10.1016/j.resourpol.2020.101815

\section{Getting to know the communities}

The CA officers at Frieda spoke openly about what they perceived as a conflicting nature of their jobs, where their professional roles and capacities were at a constant interplay with the personal ties they formed with people in the Project's impact villages. The more insights the officers were able to gain into the intricacies of social life in these communities, the more uncomfortable they seemed with the generalisations used by the company in an effort to get to know and build relations with the local stakeholders. Especially considering that the company understood those stakeholders as risk be managed (see Frederisken, 2018, on CSR as risk management mechanism) and imagined them stakeholders to be of a particular kind - lacking capacity, possessing little in terms of formal education and training, lagging behind progress and development, and in need of the forward-looking mining industry. The officers were very vocal about the need to design and deliver programmes and solutions tailored to the local contexts. They have found it difficult at times to act on their knowledge and relations with the communities within the relative rigidity of Xstrata's bureaucracy, administration and management structures.

The way that community talk is often in line with their own beliefs. But the company has its own beliefs, and its own policies. It is an international company and it seeks to standardise policies and procedures. But this causes problems for us on the ground.

This comment referred to what the CA officers saw as externally set standards and indicators, including those enforced vertically by Xstrata Plc, which framed the team's objectives in particular, auditable terms, and against which the team's work and the Project's claims of 'good citizenship' were measured. A couple made a comment about the irony of using depersonalised and objectified measurements to make positive claims about 'corporate personhood'

Our work should not be driven by ticking externally set boxes, but by the work we do on the ground, specific community development goals which are set for this Project and for these communities. 
This version was submitted to the Resources Policy Journal in July 2019. It has since been amended and published (in July 2020) following a peer-review. Please do not circulate this copy without the author's consent. Published version for citation can be found here: https://doi.org/10.1016/j.resourpol.2020.101815

In a similar vein, when explaining the work of the team, the officers would sometimes remark that 'community affairs work is different to a pure study. It is not just about ticking boxes for feasibility. It is about maturing relationships for the future stages of the Project'. Which is why, although the administrative demands of their jobs were high and required many hours spent in the office in front of a computer, members of the team tried to spend a significant portion of their time with the communities and used personal relations to get to know the local people and what the CA officers would often term 'the local custom'.

We try to find ways to understand the locals, their lifestyle, their thinking. We do this to find the right approach - one that will help the company create better relationships with the communities.

The senior team members especially voiced concerns over the risks posed by creating programmes based on cultural oversimplifications and misunderstandings. They have found it difficult to 'see like a company' (Ferguson, 2005).

To do things well here we need to look inside the culture, and really engage with how the local people think. We believe that if you agree to embed structures in fundaments different than the traditional organizing principles, this creates a serious threat for the future, it will not be sustainable.

\section{Close but not too close}

Although they are open systems, companies prefer to be left alone with their routines and avoid being entangled in relations and contexts over which they do not have control. Mining companies may have mobilized around CSR discourse, but did so in a way which largely sidesteps the issue of inequalities and conflict in resource extraction contexts, and ignores 'structural contingencies of company-community engagements' (Luning, 2012:206). Broad themes of disentanglement and detachment have featured in a number of anthropological accounts of CSR in the extractive industries to date. For example, Cross (2016:121) used an example of a diamond company to show how sustainability accounting allows companies to separate themselves 'legally, morally, and socially from binding obligations and 
This version was submitted to the Resources Policy Journal in July 2019. It has since been amended and published (in July 2020) following a peer-review. Please do not circulate this copy without the author's consent. Published version for citation can be found here: https://doi.org/10.1016/j.resourpol.2020.101815

responsibility'. He argued that the ethical accounting regimes are best described 'not as a process or a practice but as a material object: a set of written documents' (ibid.:120) which produce and act upon 'decontextualized relations and knowledge' (ibid.:111), extracting relations from local contexts, and promoting what he called "the ethics of detachment". In a similar vein, Gardner (2016:138) focused on a gas plant in Bangladesh to describe how the large, international company operating the plant used the language of 'partnerships' associated with CRD function to actively promote and enact 'ideologies of self-reliance and sustainability, geared towards the eventual disconnection of the donor rather than close, ongoing connection'. She described how the company engaged local "partners" to limit the company's direct contact with communities and remain separated from the local population, responding to contradictory pressures 'to create and celebrate partnership whilst simultaneously remaining detached' (ibid.:129). As described above, at the Frieda River Project, the company managers in Brisbane offices employed a very selective understanding of SD to limit their own exposure and push back on demands for development assistance from local communities. They interpreted CSR in a very specific way, and used the language of CSR and SD at particular moments to serve very specific ends. For example, to justify their decisions and actions designed to strategically limit their liabilities, and manage their relationship with local stakeholders in such a way as to be able to exit those relations at relatively short notice, should the company decide to leave the Project.

Mainstream CSR mechanisms reflect the industry's strive for standardisation and tend to be developed in neutral environments which ignore power inequalities and 'assume a set of conditions that do not exist in most of the world' (Newell, 2005:556). But they are implemented in complex and contested social, political and economic contexts, and require nuanced understanding and careful management of a complex web of relations. To that end, the entangled social arena of CRD field practice contrasts sharply with the detached, professional arena preoccupied with CSR (Luning, 2012:205), as CRD function demonstrates and acts upon companies' entanglements in project locations which mainstream CSR mechanisms attempt to simplify and control. By embedding themselves in local networks, CRD field practitioners enter into personal relations with the local stakeholders, and manage numerous responsibilities and obligations. They gain in-depth knowledge of the social and political environment 
This version was submitted to the Resources Policy Journal in July 2019. It has since been amended and published (in July 2020) following a peer-review. Please do not circulate this copy without the author's consent. Published version for citation can be found here: https://doi.org/10.1016/j.resourpol.2020.101815

but their on-the ground experiences do not easily align with a technical organisational culture of resource extraction companies which are driven by scientific processes and predictable and clearly measurable outcomes. This leads to a process of simplification, as the complex entanglements encountered by CRD officers are simplified, or translated, in ways that will be intelligible within the company, where the interests are more detached.

Rajak (2011a:193-4) described a sense of failure and impotence experienced by CRD practitioners in South Africa as they 'struggled to maintain relationships with community organisations in a context of shifting company policy and unpredictable resource flows' and remained 'trapped under the weight of the company's hierarchical bureaucracy and subject to internal corporate decisions over which they [have] little, if any, control'. At the Frieda River Project, the CA officers spoke of their frustration with mechanisms of CSR adopted by the company and missed opportunities for developing a meaningful CRD practice, embedded in local contexts and addressing local social goals and aspirations. They also talked about the difficulty of being held accountable (both professionally and personally) for implementing company decisions and programs, over which they had very little influence and some of which at least they did not personally support. This is not unique to Frieda. While they play a key role in implementing CSR through CRD agendas and possess intimate knowledge of local contexts, which makes them well placed to shape CRD strategies, field practitioners across the industry are commonly removed from the centre of operations and decision-making power. As argued by Kemp et al, 'operational level personnel tend to become subjects of rather than participants in deliberations about the challenges of CSR and the possibilities for improved social performance in their particular context. As a result, inherent organizational knowledge of CSR is constrained by the audit process and the opportunity for critical reflection stifled, effectively limiting "operationalization" of CSR on the ground' (Kemp et al, 2012:1). Consequently, CRD field practitioners often feel alienated from the command centre and removed from decision-making processes, despite being uniquely qualified to provide advice on best ways to enact CSR and contribute to social and development goals in project locations.

\section{Conclusions}


This version was submitted to the Resources Policy Journal in July 2019. It has since been amended and published (in July 2020) following a peer-review. Please do not circulate this copy without the author's consent. Published version for citation can be found here: https://doi.org/10.1016/j.resourpol.2020.101815

While in real terms it may have done little to address systemic power inequalities between mining companies and their local hosts, the discourse of CSR introduced new forms of relations between companies and their local stakeholders. It also introduced new regimes of accountability both in terms of changes in social and environmental accounting practice and increasing recognition of communities and host countries' rights to hold companies accountable for the impacts of their operations. CSR led to emergence of material artefacts and professional roles within organisations, aimed operationalising CSR both within business structures, and enacting it in project locations. Contributing to anthropological research on CSR in the extractives sector, analysis presented in this paper points to a potentially dangerous dissonance in CSR and its enactments at resource exploration projects. It argues that while the discourse of CSR was ultimately born out of acknowledgements of companies' entanglements in its wider operating environment, its mechanisms can and are being used to promote, to borrow Cross' turn of phrase, the ethics of detachment which allows companies to abdicate their responsibility and disentangle themselves from complex webs of social relations obligations that characterise resource exploration and extraction projects. In the case of complex ore bodies, such as the example explored here, this approach carries the danger of overlooking and oversimplifying the complexity of the project setting, increasing the project's vulnerability to ESG risks described by Valenta et al. (2019), and expose to complex risks and impacts that threaten the future of the projects.

\section{Acknowledgements:}

This work was supported by the Economic and Social Research Council UK [award number ES/1904107/1]; and the European Commission under Horizon 2020 Marie Sklodowska Curie Actions framework [MSCA-GF grant number 753272].

\section{$\underline{\text { References: }}$}


This version was submitted to the Resources Policy Journal in July 2019. It has since been amended and published (in July 2020) following a peer-review. Please do not circulate this copy without the author's consent. Published version for citation can be found here: https://doi.org/10.1016/j.resourpol.2020.101815

Appel, HC. 2012a. Walls and white elephants: Oil extraction, responsibility and infrastructural violence in Equatorial Guinea. Ethnography. Vol. 13:4. Pp. 439-465.

Appel, H. 2012b. Offshore work: Oil, modularity, and the how of capitalism in Equatorial Guinea. American Ethnologist. Vol.39:4. Pp.692-709.

Bainton, N. and JR. Owen. 2018. Zones of entanglement: Researching mining arenas in Melanesia and beyond. The Extractive Industries and Society. In Press. Accessed online in June 2019 from: https://www.sciencedirect.com/science/article/pii/S2214790X18301369

Banks, G., Kuir-Ayius, D., Kombako, D., \& B. Sagir. 2017. Dissecting Corporate Community

Development in the Large-Scale Melanesian Mining Sector. In Filer, C. and P.-Y. Le Meur (eds.)

Large-Scale Mines and Local-Level Politics: Between New Caledonia and Papua New Guinea. Pp. 207228. Canberra: ANU Press.

Bebbington, A., Hinojosa, L., Bebbington, DH., Burneo, ML. and X. Warnaars. 2008. Contention and Ambiguity: Mining and the Possibilities of Development. Development and Change. Vol 39:6. Pp. 887914.

Blowfield, M. 2007. Reasons to be cheerful? What we know about CSR's impact. Third World Quarterly. Vol. 28:4. Pp. 683-695.

Böhling, K; Murguia, D and J Godfrid. 2019. Sustainability Reporting in the Mining Sector: Exploring Its Symbolic Nature. Business \& Society. Vol. 58:1. Pp. 191-225.

Carroll, A. 1999. Corporate Social Responsibility: Evolution of a Definitional Construct. Business Society. Vol. 38:3. Pp. 268-295.

Cross, J. 2016. Detachment as a corporate ethic: Materializing CSR in the diamond supply chain. In Dolan, C and D Rajak (eds.) The Anthropology of Corporate Social Responsibility. Pp. 110-127. London and New York: Berghahn. 
This version was submitted to the Resources Policy Journal in July 2019. It has since been amended and published (in July 2020) following a peer-review. Please do not circulate this copy without the author's consent. Published version for citation can be found here: https://doi.org/10.1016/j.resourpol.2020.101815

Dahlsrud, A. 2008. How corporate social responsibility is defined: an analysis of 37 definitions.

Corporate social responsibility and environmental management. Vol. 15:1. Pp.1-13.

Duarte, F. 2011. What Does a Culture of Corporate Social Responsibility “Look” Like? A Glimpse into a Brazilian Mining Company. International Journal of Business Anthropology. Vol. 2:1. Pp. 106-122.

Duarte, F. 2010. Working with Corporate Social Responsibility in Brazilian Companies: The Role of Managers' Values in the Maintenance of CSR Cultures. Journal of Business Ethics. Vol. 96. Pp. 355-368.

Ferguson, J. 2005. Seeing like an oil company: space, security, and global capital in neoliberal Africa. American anthropologist. Vol. 107:3. Pp.377-382.

Ferguson, J. 1990. The Anti-Politics Machine: “Development”, repoliticizatoin and bureaucratic power in Lesotho. Cambridge: Cambridge University Press.

Frederiksen, T. 2018. Corporate social responsibility, risk and development in the mining industry. Resources Policy. Vol. 59. Pp.495-505.

Friedman, M. 2007 [1970]. The Social Responsibility of Business is to Increase its Profits. In Zimmerli, W., Richter, K. and M. Holzinger (eds.) Corporate Ethics and Corporate Governance. Berlin: SpringerVerlag.

Gardner, K. 2016. Disconnect Development: Imagining Partnershpi and Experiencing Detachment in Chevron's Borderlands. In Dolan, C and D Rajak (eds.) The Anthropology of Corporate Social Responsibility. Pp. 128 - 151. London and New York: Berghahn.

Gilberthorpe, E. and G. Banks. 2012. Development on whose terms? CSR discourse and social realities in Papua New Guinea's extractive industries sector. Resources Policy. Vol. 37:2. Pp. 185-193.

Gray, R. 2002. The social accounting project and Accounting Organizations and Society: Privileging engagement, imaginings, new accountings and pragmatism over critique?. Accounting, Organizations and Society. Vol. 27:7. Pp. 687-708. 
This version was submitted to the Resources Policy Journal in July 2019. It has since been amended and published (in July 2020) following a peer-review. Please do not circulate this copy without the author's consent. Published version for citation can be found here: https://doi.org/10.1016/j.resourpol.2020.101815

Harvey, B. 2014. Social development will not deliver social license to operate for the extractive sector. The Extractive Industries and Society. Vol. 1. Pp. 7-11.

Humphreys, D. 2000. A business perspective on community relations in mining. Resources Policy. Vol. 26. Pp. $127-131$.

Hunoldt, M; Oertel, S and A Galander. 2018. Being Responsible: How Managers Aim to Implement corporate Social Responsibility. Business \& Society. p.0007650318777738.

Kemp, D. 2010. Community Relations in the Global Mining Industry: Exploring the Internal Dimensions of Externally Oriented Work. Corporate Social Responsibility and Environmental Management. Vol. 17. Pp. 1-14.

Kemp, D. 2009. Mining and community development: problems and possibilities of local-level practice. Community Development Journal. Vol. 45:2. Pp. 198-218.

Kemp, D. and JR. Owen. 2013. Community relations and mining: Core to business but not "core business". Resources Policy. Vol. 38, pp. 523-531.

Kemp, D., Owen, JR. and S. van de Graaff. 2012. Corporate social responsibility, mining and "audit culture”. Journal of Cleaner Production. Vol. 24. Pp. 1-10.

Killian, S. and P. O'Regan. 2016. Social accounting ant the co-creation of corporate legitimacy. Accounting, Organizations and Society. Vol. 50. Pp. 1-12.

Luning, S. 2012. Corporate Social Responsibility (CSR) for exploration: Consultants, companies and communities in processes of engagements. Resources Policy. Vol. 37. Pp. 205-211.

Macintyre, M., Mee, W. and F. Solomon. 2008. Evaluating Social Performance in the Context of an “Audit Culture”: a Pilot Social Review of a Gold Mine in Papua New Guinea. Corporate Social Responsibility and Environmental Management. Vol. 15:2. Pp. 100-110.

Mintzberg, H. 1983. The case for Corporate Social Responsibility. Journal of Business Strategy. Vol. 4:2. Pp. 3-15. 
This version was submitted to the Resources Policy Journal in July 2019. It has since been amended and published (in July 2020) following a peer-review. Please do not circulate this copy without the author's consent. Published version for citation can be found here: https://doi.org/10.1016/j.resourpol.2020.101815

Newell, P. 2005. Citizenship, accountability and community: the limits of the CSRM agenda. International Affairs. Vol. 81:3. Pp. 541-557

Newman, J. 2005. Constructing Accountability: Network Governance and Managerial Agency. Public Policy and Administration. Vol. 19:4. Pp. 17-33.

Owen, JR and D Kemp. 2014. Mining and community relations: Mapping the internal dimensions of practice. The Extractive Industries and Society. Vol. 1. Pp. 12-19.

Panaust. 2018, Dec. A nation-building development pathway for the Frieda River Project. Company announcement. Accessed in June 2019 from: https://panaust.com.au/company-announcements.

Porter, ME and MR Kramer. 2006. Strategy and Society: The Link Between Competitive Advantage and Corporate Social Responsibility. Harvard Business Review. Vol. 84:12. Pp. 1-13.

Power, M. 1999. The Audit Society: Rituals of Verification. Oxford: Oxford University Press.

Power, M. 2000. The Audit Society - Second Thoughts. International Journal of Auditing. Vol. 4:1. Pp. 111-119.

Power, M. 2003. Evaluating the Audit Explosion. Law \& Policy. Vol. 25:3. Pp. 185-202.

Rajak, D. 2011a. In Good Company: An Anatomy of Corporate Social Responsibility. Stanford, CA: Stanford University Press.

Rajak, D. 2011b. Theatres of virtue: Collaboration, consensus, and the social life of corporate social responsibility. Focaal - Journal of Global and Historical Anthropology. Vol. 60. Pp. 9-20.15

Scott, JC. 1998. Seeing Like a State: How Certain Schemes to Improve Human Condition Have Failed. London: Yale University Press.

Sethi, SP., Martell, TF. and M. Demir. 2016. Building corporate reputation through corporate social responsibility (CSR) reports: the case of extractive industries. Corporate Reputation Review. Vol. 19:3. Pp.219-243. 
This version was submitted to the Resources Policy Journal in July 2019. It has since been amended and published (in July 2020) following a peer-review. Please do not circulate this copy without the author's consent. Published version for citation can be found here: https://doi.org/10.1016/j.resourpol.2020.101815

Sydow, J. 2016. Global Concepts in Local Contexts: CSR as "Anti-Politics Machine" in the Extractive Sector in Ghana and Peru. In Dolan, C and D Rajak (eds). The Anthropology of Corporate Social Responsibility. London and New York: Berghahn. Pp. 217-242.

Utting, P. 2005. Corporate responsibility and the movement of business. Development in Practice. Vol.15:3-4. Pp. 375-388.

Valenta, R.K., Kemp, D., Owen, J.R., Corder, G.D. and É. Lèbre. 2019. Re-thinking complex orebodies: Consequences for the future world supply of copper. Journal of Cleaner Production. 220. Pp.816-826.

Welker, M. 2014. Enacting the corporation: An American Mining Firm in Post-Authoritarian Indonesia. London: University of California Press.

Xstrata Copper. 2008. Frieda River Project Sustainability Report 2007. Brisbane: Xstrata Copper. 